\title{
A Slow-Release Fertilizer of Urea Prepared via Melt Blending with Degradable Poly(lactic acid): Formulation and Release Mechanisms
}

\author{
Mujtahid Kaavessina *, Sperisa Distantina and Esa Nur Shohih
}

Citation: Kaavessina, M.; Distantina, S.; Shohih, E.N. A Slow-Release Fertilizer of Urea Prepared via Melt Blending with Degradable Poly(lactic acid): Formulation and Release Mechanisms. Polymers 2021, 13, 1856. https://doi.org/10.3390/ polym13111856

Academic Editors: Célio Bruno Pinto Fernandes, Salah Aldin Faroughi, Luís L. Ferrás and Alexandre M. Afonso

Received: 20 April 2021

Accepted: 29 May 2021

Published: 3 June 2021

Publisher's Note: MDPI stays neutral with regard to jurisdictional claims in published maps and institutional affiliations.

Copyright: (C) 2021 by the authors Licensee MDPI, Basel, Switzerland. This article is an open access article distributed under the terms and conditions of the Creative Commons Attribution (CC BY) license (https:/ / creativecommons.org/licenses/by/ $4.0 /)$.

\author{
Chemical Engineering, Universitas Sebelas Maret, Surakarta 57126, Indonesia \\ sperisa_distantina@staff.uns.ac.id (S.D.); esanurshohih@gmail.com (E.N.S.) \\ * Correspondence: mkaavessina@staff.uns.ac.id
}

\begin{abstract}
In this research, a low molecular weight poly(lactic acid) (or PLA) synthesized from direct polycondensation was melt compounded with urea to formulate slow-release fertilizer (SRF). We studied the influence of the molecular weight $\left(M_{\mathrm{W}}\right)$ of PLA as a matrix and the urea composition of SRF towards release kinetics in water at $30{ }^{\circ} \mathrm{C}$. The physical appearance of solid samples, the change in urea concentration, and acidity $(\mathrm{pH})$ of water were monitored periodically during the release test. Three studied empirical models exhibited that diffusion within the matrix dominated the urea release process, especially when the release level was less than $60 \%$. Thus, a lower $M_{\mathrm{W}}$ of PLA and a higher urea content of SRF showed a faster release rate. For the entire length of the release experiment, a combination of diffusion and degradation mechanisms exhibited the best agreement with the experimental data. The hydrolytic degradation of PLA may begin after $96 \mathrm{~h}$ of immersion (around 60\% release level), followed by the appearance of some micro-holes and cracks on the surface of the SRF samples. Generally, this research revealed the good release performance of urea without residues that damage the soil structure and nutrient balance.
\end{abstract}

Keywords: poly(lactic acid); urea; melt blending; slow-release fertilizer

\section{Introduction}

The global consumption of agricultural products has steadily increased proportionally with world population growth. Rice, maize, and wheat are the most important cereals worldwide in terms of production. Nowadays, agricultural intensification is the main alternative that encourages farmers to increase agricultural production with limited agricultural land. Exploiting natural resources, such as soil, water, space, or energy, is necessary for every stage of large-scale agriculture. Many reports have described the depletion of organic matter, chemical contamination of soil, decreased soil fertility, and water spring deterioration related to agricultural products [1-3]. The main challenge has become to increase the quantity and quality of crops product via sustainable agriculture.

Fertilization is an effort to restore soil fertility that plays an important role in crop production. Thus, it contributes primarily and directly to the production costs. Pypers et al. reported that the key to successful plant fertilization is the appropriate dosage and timing of fertilization [4]. Improper fertilization techniques, inappropriate fertilization times, and both excessive and insufficient fertilizer doses contribute to detrimental effects on the environment. Indeed, this condition affects the quality and quantity of agricultural products.

Urea is very widely used in agriculture, known as nitrogen fertilizer, because of its high nitrogen content $(46 \%)$. Nitrogen is a necessary nutrient for plant growth, and it is the most crucial factor commonly considered to be yield-limiting. The conversion mechanism of how urea becomes nitrogen absorbable by plants in the form of ammonium $\left(\mathrm{NH}_{4}{ }^{+}\right)$and nitrate $\left(\mathrm{NO}_{3}{ }^{-}\right)$is known well $[5,6]$. The urease enzyme in moist soil will encourage the nitrogen in urea to be converted into ammonium $\left(\mathrm{NH}_{4}{ }^{+}\right)$via hydrolysis. In 
the nitrification process, ammonium is converted into nitrite $\left(\mathrm{NO}_{2}^{-}\right)$and then to nitrate $\left(\mathrm{NO}_{3}{ }^{-}\right)$by oxidation [5]. However, many factors can easily eliminate both substances $\left(\mathrm{NH}_{4}{ }^{+}\right.$ and $\mathrm{NO}_{3}{ }^{-}$) from soils, such as drainage; denitrification of nitrate-producing nitrous oxide gas $\left(\mathrm{N}_{2} \mathrm{O}\right)$, nitric oxide gas $(\mathrm{NO})$, or nitrogen gas $\left(\mathrm{N}_{2}\right)$; nitrogen volatilization; and surface run-off [7]. Thus, it has been estimated that only $30-50 \%$ of the nitrogen in urea can be absorbed by plants $[8,9]$.

Many efforts have been studied and applied to reduce the loss of nitrogen and to conserve and protect our environment, such as (i) fertilization management: integrated and site-specific management, and balanced fertilization: (ii) chemical additives such as nitrification inhibitors; and (iii) modification of fertilizer properties: controlled/slowrelease fertilizer (CRF or SRF) $[10,11]$. In the last decade, CRF/SRF has become an exciting topic for researchers in academia and industry.

SRF is the type of fertilizer that releases nutrient elements slowly and regularly, approaching the absorption patterns of plants. The nutrient elements contained in the fertilizers do not get carried away by the water. The synthesis of SRF combines fertilizer (such as urea) and other materials with water retention properties. Recently, three methods were developed to produce SRF, i.e., (i) chemically combined fertilizers, (ii) coated fertilizers, and (iii) physically blended fertilizers $[8,9,12]$.

In SRF formulation, commercial or developed SRFs mostly utilize materials such as urea-formaldehyde (UF), sulfur, zeolite or modified zeolite, bentonite, polyolefin, polyvinylidene chloride, polystyrene, etc. These materials are used alone or in combination with others as coatings, matrices, carriers, or grafted materials in SRFs [12-16], which do not easily degrade properly in the soil. These accumulated residues of SRFs allow damage to the soil structure and nutrient balance in the soil. Therefore, the research focus trend has been switched to exploiting safer and environmentally friendly materials that can also control the release rate of SRF.

This problem inspired the idea of utilizing low molecular weight poly(lactic acid) as a fertilizer carrier matrix. As known, poly(lactic acid) is not polluting to the environment after it has naturally degraded in a humid environment or a solution. It could decompose into natural products/biomass and gasses that are not harmful/toxic to the crop plants $[17,18]$. Thus, there is no residual accumulation in the use of this material in SRF formulations.

In our previous work, the degradation rate of poly(lactic acid) or PLA was affected by other polymers or substances in blends or its molecular weight $[19,20]$. Based on the results, we studied the possibility of developing fertilizer by utilizing low molecular weight PLA as a substitute for the existing matrices of SRF. The objectives of this research were: (i) to formulate slow-release fertilizer (SRF) of urea by exploiting the potential properties of low molecular weight $\left(M_{\mathrm{W}}\right)$ PLA as a matrix, and (ii) to study the urea release mechanisms of SRF through three mathematical model approaches.

We blended micro-size urea into the melt of low molecular weight PLA obtained through direct polycondensation of lactic acid to achieve the objectives. Different loadings of urea in matrix and molecular weights of PLA were analyzed regarding their release behavior. The presence of urea in the SRF was detected by Fourier transform infra-red (FTIR). The release of urea in the SRF was studied through a static release experiment designed mainly according to the other research methods [8,9]. The concentration of urea in the solution was recorded, as well as its acidity $(\mathrm{pH})$. Before and after the release test, a morphological analysis of the samples was conducted by scanning electron microscopy (SEM).

\section{Materials and Methods}

The lactic acid in a $88-90 \%$ aqueous solution was produced by Scharlau (Barcelona, Spain) with a density of $1.20\left(20^{\circ} / 4^{\circ}\right)$. Stannous (II) chloride dihydrate $(98 \%)$, urea powder, and chloroform were ordered from Sigma-Aldrich (Jakarta, Indonesia). Methanol was produced by Avonchem (Macclesfield, UK). All chemicals were used as received without any additional purification. 
Direct polycondensation of lactic acid was carried out without any solvents in the $500 \mathrm{~mL}$ flat-bottom 3-necked flasks completed by a Dean-Stark trap. Nitrogen flowed into this flask through a capillary inlet. The reaction condition was controlled at $138^{\circ} \mathrm{C}$ and stirred at $150 \mathrm{rpm}$ using a magnetic heat stirrer, RCT Basic IKAMAG ${ }^{\circledR}$ safety control. Stannous (II) chloride as the catalyst was added at about $0.1 \mathrm{wt} \%$.

Micro-sized urea was blended in a micro-compounder at $50 \mathrm{rpm}$ and $110{ }^{\circ} \mathrm{C}$ for $1 \mathrm{~min}$. The granulation process was carried out by dripping the molten SRF on a tray. The nomenclature of samples prepared and analyzed in this investigation is shown in Table 1.

Table 1. Nomenclature of samples.

\begin{tabular}{cccc}
\hline Sample & Polymerization Time, $\mathbf{h}$ & Average $\boldsymbol{M}_{\mathbf{w}}$ of PLA, Da & Urea Content in $\mathbf{3} \mathbf{g}$ of SRF, $\mathbf{g}$ \\
\hline Neat PLA & 16 & 6015.2 & 0 \\
SRF101 & 16 & 6015.2 & 0.01 \\
SRF201 & 24 & $10,264.7$ & 0.01 \\
SRF301 & 32 & $13,564.2$ & 0.01 \\
SRF203 & 24 & $10,264.7$ & 0.03 \\
SRF205 & 24 & $10,264.7$ & 0.05 \\
\hline
\end{tabular}

The average molecular weight of synthesized PLA was determined at $30{ }^{\circ} \mathrm{C}$ by a Waters Alliance GPCV 2000 system. Tetrahydrofuran (THF) as the mobile phase was set at a flow rate of $1 \mathrm{~mL} / \mathrm{min}$. The presence of urea in formed SRF was detected using a PerkinElmer 630 IR spectrophotometer (FTIR) within the IR spectrum range of $4000-400 \mathrm{~cm}^{-1}$.

A static release experiment was performed at room temperature (around $30^{\circ} \mathrm{C}$ ). Figure 1 depicts the experimental apparatus for determining the static release of urea in water, emulating previous research $[8,9]$. A small magnetic stirrer bar (3 $\mathrm{mm}$ diameter and $6 \mathrm{~mm}$ long) was used to stir the samples at $50 \mathrm{rpm}$. SRF samples $(3 \mathrm{~g})$ were put into a tube, $25 \mathrm{~mm}$ long and $5 \mathrm{~mm}$ in diameter, with one end closed. The tube containing the SRF was placed horizontally in a glass beaker $(150 \mathrm{~mL})$ filled with $100 \mathrm{~mL}$ of water. Periodically, the urea concentration and the acidity $(\mathrm{pH})$ of water were recorded. Urea was detected using a Genesis 20 Visible spectrophotometer (Thermo Scientific, Waltham, MA, USA) operating at a wavelength of $440 \mathrm{~nm}$ assisted by Ehrlich reagent. The urea concentration was calculated using a standard curve that correlated the urea concentration and absorbency value on the spectrophotometer reading. The degraded solids of SRFs were observed regarding their morphology via scanning electron microscopy (SEM), JEOL JSM-6360A (Tokyo, Japan), at $15 \mathrm{kV}$.

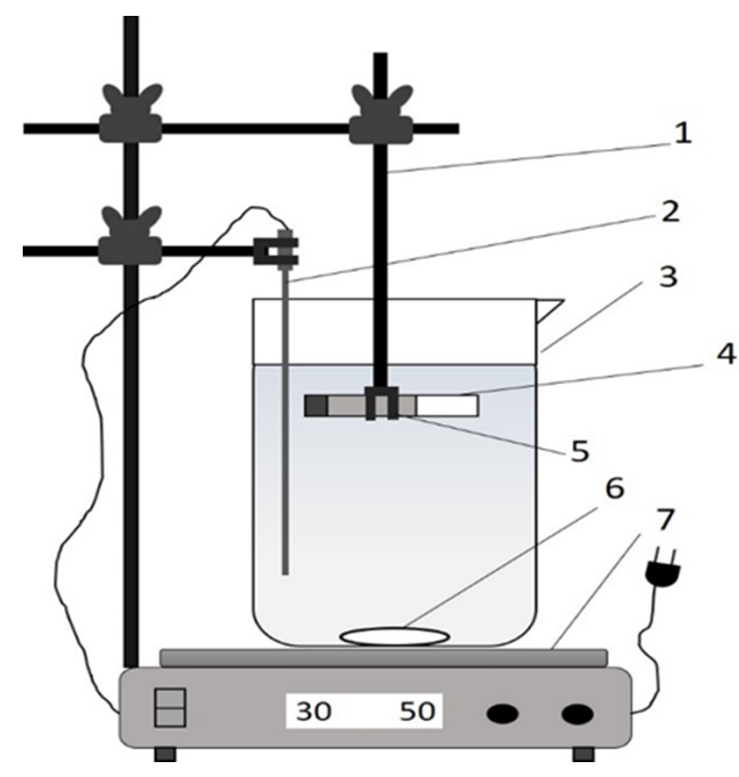

Figure 1. Scheme of the static release apparatus: 1 Tripod and clamp, 2 thermocouple (PT1000), 3 glass beaker, 4 sample tube, 5 SRF sample, 6 magnetic stirrer bar, and 7 magnetic heat stirrer. 
Three mathematical models were applied to analyze the release mechanism by fitting the curve of the fractional release, i.e., (i) the Korsmeyer-Peppas model, (ii) the diffusionrelaxation model, and (iii) the diffusion-degradation model. OriginPro software 2016 assisted in plotting the nonlinear fit of the three models to determine the parameter constants.

The first model only considers the diffusion that occurred during urea release, as presented below [21,22]:

$$
\frac{M_{t}}{M_{\infty}}=k t^{n}
$$

where $M_{t}$ is the amount of urea released at time $t(\mathrm{~g}), M_{\infty}$ is the amount of urea released over an infinite time or the total amount of urea when it is all released from the SRF sample $(\mathrm{g})$, and $t$ is the time of urea release $(\mathrm{m})$. The $k$ value is the kinetic constant, combining the characteristics of the urea-SRF system, and $n$ is the release exponent, representing a transport mechanism, whereas $M_{t} / M_{\infty}$ refers to the fraction of urea released in water at time $t$. In the diffusion-relaxation model, 2 constants refer to the diffusion and the relaxation, as formulated below $[8,23,24]$ :

$$
\frac{M_{t}}{M_{\infty}}=k_{1} t^{m}+k_{2} t^{2 m}
$$

where $k_{1}$ and $k_{2}$ are associated with diffusion and relaxation, respectively. The $m$ value is determined to be 0.43 , based on the geometric shape of SRF representing the diffusion exponent [23]. For the diffusion-degradation model, there is 1 constant related to diffusion and 3 constants related to degradation, as defined below:

$$
\frac{M_{t}}{M_{\infty}}=a t^{0.5}+b t+c t^{2}+d t^{3}
$$

where $a$ is associated with diffusion and the 3 constants $(b, c$ and $d)$ are associated with degradation.

\section{Results and Discussion}

Lactic acid was polymerized solely without any solvents through direct polycondensation. Stannous chloride dihydrate $\left(\mathrm{SnCl}_{2} \cdot 2 \mathrm{H}_{2} \mathrm{O}\right)$ was added as the catalyst and the temperature was set at $138^{\circ} \mathrm{C}$ during polymerization. As seen in Table 1 , the average molecular weight of poly(lactic acid) obtained varied in accordance with the polymerization time. The polycondensation time of lactic acid varied at 16, 24, and $32 \mathrm{~h}$ and resulted in an average molecular weight of $6015.2 \mathrm{Da}, 10,264.7 \mathrm{Da}$, and 13,564.2 Da, respectively. Further, this obtained poly(lactic acid) was blended with micro-sized urea to make slow-release fertilizer (SRF), as summarized in Table 1.

\subsection{Molecular Structure of Slow-Release Fertilizer (SRF)}

The SRF's structure was investigated using an infra-red (IR) spectrophotometer to verify urea and PLA's successful blending through melt blending. Figure 2 shows the IR spectra of some samples. The neat PLA sample (Figure 2A) was also scanned to determine urea's presence in slow-release fertilizer. Five dominant peaks show the functional group of poly(lactic acid). The wavenumber around $870 \mathrm{~cm}^{-1}$ shows the peak representing the bond of $-\mathrm{C}-\mathrm{C}-$. This peak also indicates the semi-crystalline phase of the obtained PLA. The methyl groups $-\mathrm{CH}-$ or $-\mathrm{CH}_{3}$ appear at the wavenumber around $2944 \mathrm{~cm}^{-1}$ and $1382 \mathrm{~cm}^{-1}$ with different vibration modes. Garlotta [25] explained that stretching and bending modes are represented by the peaks at $2944 \mathrm{~cm}^{-1}$ and $1382 \mathrm{~cm}^{-1}$, respectively. The peaks at the wavenumbers around $1740 \mathrm{~cm}^{-1}, 1093 \mathrm{~cm}^{-1}$ and $1182 \mathrm{~cm}^{-1}$ represent the carboxyl group's presence, i.e., $\mathrm{C}=\mathrm{O}$ and $\mathrm{C}-\mathrm{O}$ with the same vibration mode (stretching).

Only three peaks appear on the IR spectra of the SRF samples, i.e., around $3472 \mathrm{~cm}^{-1}$, $1585 \mathrm{~cm}^{-1}$, and $1560 \mathrm{~cm}^{-1}$ (Figure 2B, C and D). These peaks represent the groups of $\mathrm{N}-\mathrm{H}$ stretching, $\mathrm{N}-\mathrm{H}$ deformation, and $\mathrm{C}-\mathrm{N}$ stretching, respectively [26]. Based on this analysis, the urea in slow-release fertilizer can be detected and proven qualitatively. 


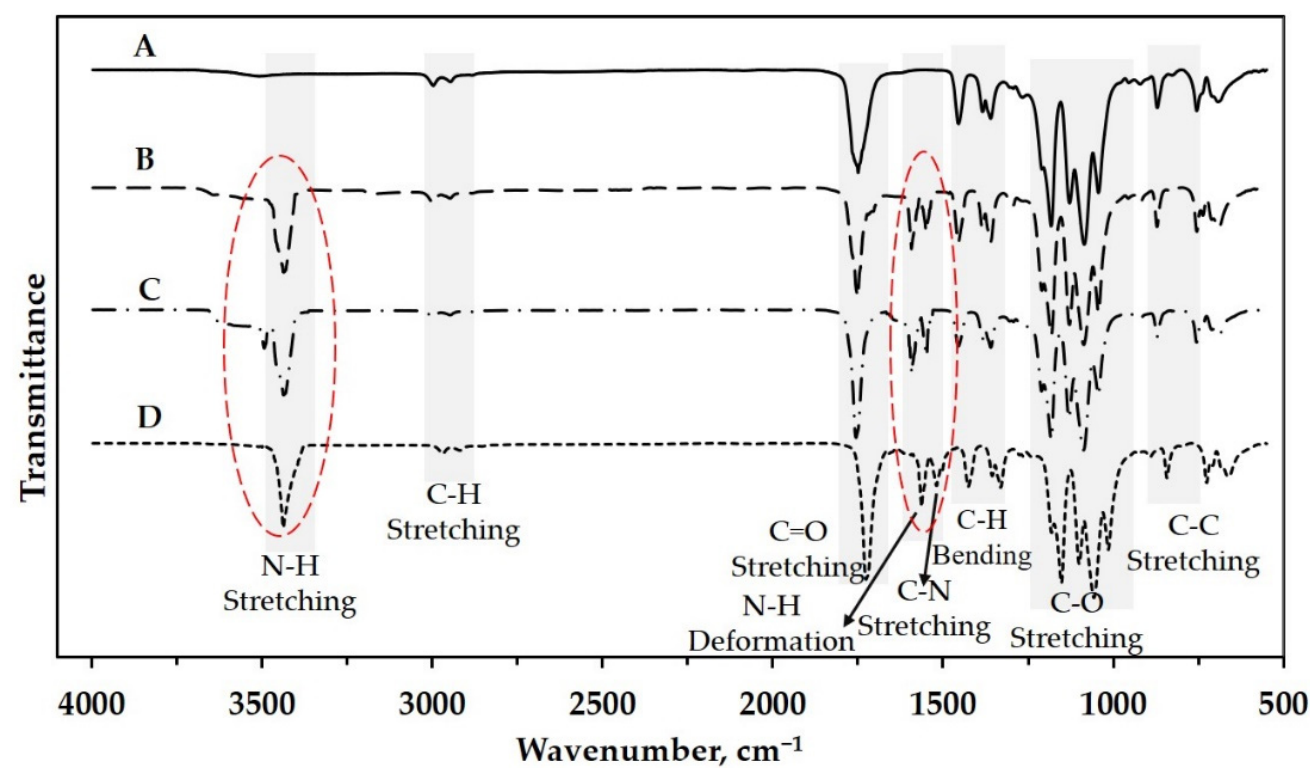

Figure 2. IR spectra of (A) neat PLA and some slow-release fertilizer: (B) SRF101, (C) SRF201, and (D) SRF301.

\subsection{Urea Release Behavior}

Further, all samples were then tested in the static release apparatus (Figure 1) to study their urea release behavior in water. This test provides two data simultaneously relating to the change in the urea concentration and the acidity $(\mathrm{pH})$ of water. Table S1 (in the Supplementary Materials) tabulates data on the urea concentration in water during the release test. These data were then processed to calculate the accumulated fraction of urea released in water during the immersion, as depicted in Figure 3. The release fraction presents information on the amount of urea released at time $t$ compared with the total urea in the SRF sample. As observed during the release test, there is no visible swelling of SRF.

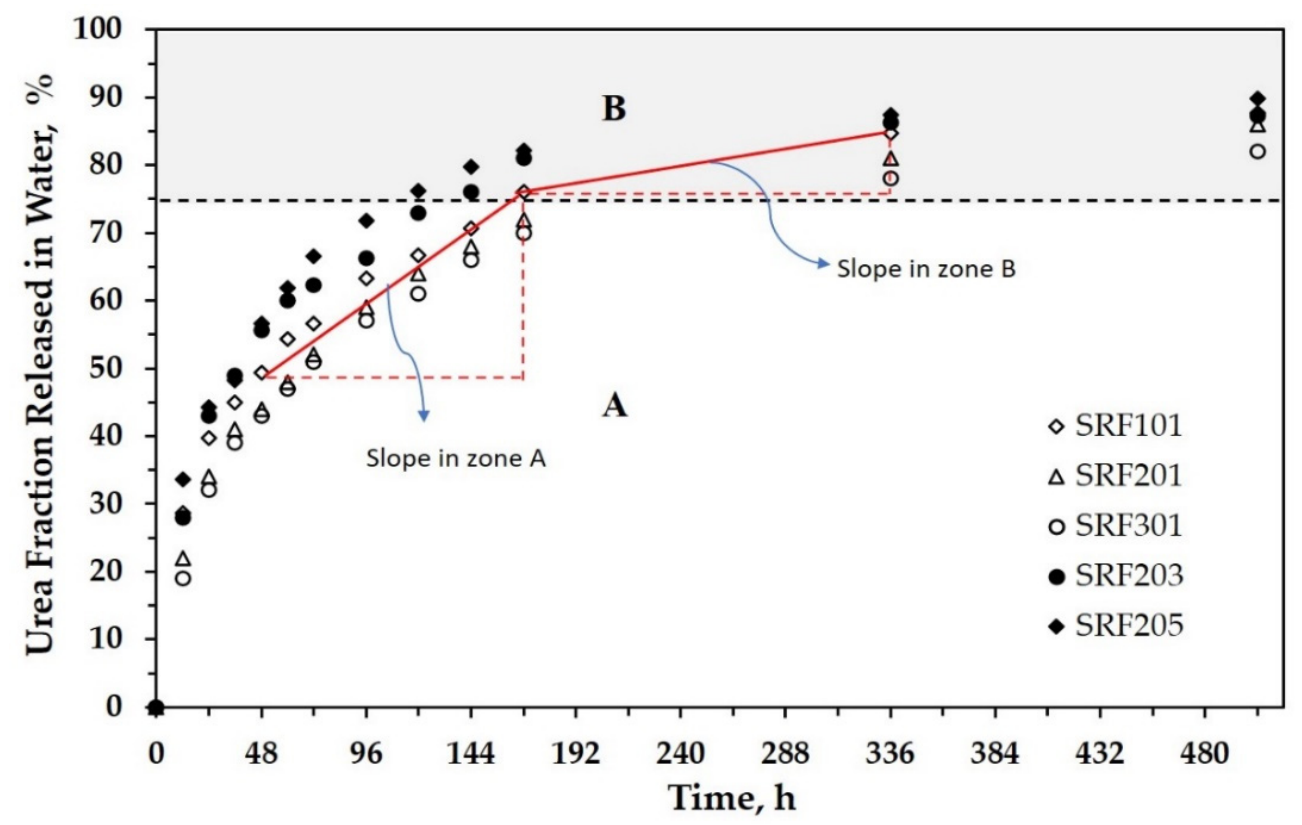

Figure 3. Fractional release of urea as a function of time for all SRF samples.

Figure 3 can be divided virtually into two zones (A and B). As seen, urea's release appears to find the release equilibrium at around $75 \%$. For all samples, the slope of urea release in Zone A is sharper than that in Zone B. This shows that urea was released rapidly in the first stage (Zone A), then the release rate tended to be slow in Zone B. For example, 
the fraction of released urea in Zone A for SRF101 changed by about 25\% within $120 \mathrm{~h}$ (in the range of $48-168 \mathrm{~h}$ ). In Zone $\mathrm{B}$, it required a time of around $168 \mathrm{~h}$ (in the range of $168-336 \mathrm{~h}$ ) to achieve an additional urea release of $12.5 \%$. The increasing concentration of urea in SRF urged the urea release to be faster. After immersion for $96 \mathrm{~h}$, the percentage of urea release reached about $59 \%, 66 \%$, and $72 \%$ for urea concentrations of $1 \%$ (SRF201), $3 \%$ (SRF203), and 5\% (SRF205), respectively. This phenomenon proves that urea, with its hygroscopic property, still existed and affected the release process.

The other phenomenon that can be highlighted is the molecular weight $\left(M_{\mathrm{w}}\right)$ of poly(lactic acid) itself. This parameter describes the length of PLA chains, which have different properties. Utilizing the higher $M_{\mathrm{w}}$ of poly(lactic acid) tended to inhibit the urea release. After immersion for $96 \mathrm{~h}$, the percentage of urea release was monitored at $63 \%$, $59 \%$, and $57 \%$ when the $M_{\mathrm{W}}$ of PLA was 6015.2 Da (SRF101), 10,264.7 Da (SRF201), and 13,564.2 Da (SRF301), respectively. This showed that the permeability of PLA decreased with increasing molecular weight so that the contact of water and urea in the PLA matrix was increasingly inhibited. Further explanations are discussed in the modeling section.

The utilization of the low molecular weight poly(lactic acid) as a matrix of SRF aimed to exploit its degradable property. Qi et al. reported a review of the biochemical processes of PLA degradation. They concluded that those processes mainly included chemical hydrolysis and biodegradation in the natural soil microcosm [17]. The presence of ester bonds in PLA can be broken with the chemical hydrolysis that may occur during the PLA's immersion. Carboxylic acid and alcohol arise as a result of breaking the ester bonds. Indeed, the existence of carboxylic acid influences the acidity of the solution. Instead, the urea initially tends to be alkaline when it dissolves in water [27]. Thus, the monitored $\mathrm{pH}$ values of solutions describe the result of combining properties between carboxylic acid and urea dissolved in water. The changes in the solution acidity are tabulated periodically in Table 2.

Table 2. Changes in acidity $(\mathrm{pH})$ during the urea release test.

\begin{tabular}{ccccccc}
\hline \multirow{2}{*}{ Time, h } & \multicolumn{7}{c}{ Acidity (pH) of Solution } \\
\cline { 2 - 7 } & Neat PLA & SRF101 & SRF201 & SRF301 & SRF203 & SRF205 \\
\hline 0 & $6.80 \pm 0.01$ & $6.80 \pm 0.01$ & $6.80 \pm 0.01$ & $6.80 \pm 0.01$ & $6.80 \pm 0.01$ & $6.80 \pm 0.01$ \\
12 & $6.79 \pm 0.02$ & $7.27 \pm 0.05$ & $6.95 \pm 0.08$ & $6.97 \pm 0.05$ & $7.19 \pm 0.05$ & $7.26 \pm 0.06$ \\
24 & $6.78 \pm 0.02$ & $7.39 \pm 0.05$ & $7.08 \pm 0.03$ & $7.06 \pm 0.05$ & $7.33 \pm 0.06$ & $7.43 \pm 0.04$ \\
32 & $6.76 \pm 0.02$ & $7.52 \pm 0.06$ & $7.15 \pm 0.03$ & $7.16 \pm 0.06$ & $7.41 \pm 0.06$ & $7.59 \pm 0.03$ \\
48 & $6.75 \pm 0.01$ & $7.55 \pm 0.03$ & $7.20 \pm 0.03$ & $7.23 \pm 0.07$ & $7.54 \pm 0.05$ & $7.70 \pm 0.03$ \\
60 & $6.74 \pm 0.01$ & $7.38 \pm 0.03$ & $7.29 \pm 0.08$ & $7.33 \pm 0.05$ & $7.67 \pm 0.04$ & $7.81 \pm 0.03$ \\
72 & $6.72 \pm 0.01$ & $7.22 \pm 0.05$ & $7.35 \pm 0.08$ & $7.34 \pm 0.03$ & $7.71 \pm 0.06$ & $7.63 \pm 0.05$ \\
96 & $6.69 \pm 0.02$ & $7.19 \pm 0.04$ & $7.33 \pm 0.07$ & $7.29 \pm 0.04$ & $7.57 \pm 0.06$ & $7.58 \pm 0.05$ \\
120 & $6.62 \pm 0.04$ & $7.16 \pm 0.03$ & $7.25 \pm 0.07$ & $7.20 \pm 0.06$ & $7.51 \pm 0.08$ & $7.52 \pm 0.03$ \\
144 & $6.50 \pm 0.04$ & $7.08 \pm 0.05$ & $7.16 \pm 0.05$ & $7.15 \pm 0.08$ & $7.50 \pm 0.06$ & $7.48 \pm 0.04$ \\
168 & $6.45 \pm 0.03$ & $7.01 \pm 0.03$ & $7.10 \pm 0.06$ & $7.13 \pm 0.05$ & $7.44 \pm 0.05$ & $7.43 \pm 0.02$ \\
336 & $6.34 \pm 0.04$ & $6.96 \pm 0.05$ & $7.04 \pm 0.05$ & $7.06 \pm 0.04$ & $7.38 \pm 0.03$ & $7.37 \pm 0.03$ \\
504 & $6.20 \pm 0.03$ & $6.92 \pm 0.04$ & $6.99 \pm 0.03$ & $7.01 \pm 0.09$ & $7.31 \pm 0.06$ & $7.33 \pm 0.06$ \\
\hline
\end{tabular}

In Table 2, for neat PLA, the acidity $(\mathrm{pH})$ tends to be constant or decrease slightly in the time range between 0 and $96 \mathrm{~h}$, then becomes relatively more apparent with increasing time above $96 \mathrm{~h}$. This means that the hydrolytic degradation may begin after $96 \mathrm{~h}$, which is indicated by the release of acid resulting from scission of the PLA chain. All samples of SRF showed the same tendency. The $\mathrm{pH}$ increased gradually and was followed by a decrease during the range of immersion time. This exciting phenomenon could be explained by the urea release causing the increasing $\mathrm{pH}$ of the solution, then the acid from PLA degradation decreasing the $\mathrm{pH}$ solution. This statement will be analyzed using the mathematical models, as discussed in this article.

By using $\mathrm{pH}$ values, the initial degradation time can be observed at different times. The degradation time of SRF101, SRF201 and SRF301 was initiated around 60, 72 and $72 \mathrm{~h}$, 
respectively. This means that increasing the molecular weight of PLA caused a shift to the longer initial degradation time. This statement is confirmed by the morphological sample after immersion at a specific time.

\subsection{Modeling of Urea Release Behavior}

Some researchers have reported several mathematical models associated with the release mechanisms of an active substance from a matrix. These models were developed via different approaches, considering (i) only the diffusion and (ii) the combination of diffusion and other factors such as relaxation and erosion/degradation [22,23,28]. In this article, three mathematical models were used to analyze the release mechanism by fitting the curve of the fractional release, i.e., the Korsmeyer-Peppas model, the diffusion-relaxation model, and the diffusion-degradation model. We examined and verified the fit of the curves of the experimental data with these developed models. The proper model will be applied to describe the release mechanism and explain the studied variables, i.e., the molecular weight of poly(lactic acid) and the urea concentration in SRF.

The Korsmeyer-Peppas model is a simple exponential expression to analyze the controlled release behavior of an active substance from its matrices. Table 3 recapitulates the data from fitting the curve of the fractional release of urea using the KorsmeyerPeppas model. This model elaborates the values of $n$ depending on the geometric shape of the sample. For the spherical form, $n<0.43$ corresponds to Fickian diffusion, while $0.43<n<0.85$ represents anomalous transport (non-Fickian diffusion) [21]. It can be seen that all samples of SRF exhibit Fickian diffusion. This table also presents $R^{2}$, which shows how close the data are to the fitted regression line. Based on the $R^{2}$ values, all the samples release curves have good enough agreement with this model.

Table 3. Diffusion parameters from the Korsmeyer-Peppas model.

\begin{tabular}{ccccc}
\hline \multirow{2}{*}{ Sample } & \multicolumn{4}{c}{ Diffusion/Korsmeyer-Peppas Model } \\
\cline { 2 - 5 } & $\boldsymbol{k}$ & $\boldsymbol{n}$ & $\boldsymbol{R}^{\mathbf{2}}$ & Type of Diffusion \\
\hline Neat PLA & - & - & - & - \\
SRF101 & $0.1796 \pm 0.0157$ & $0.2663 \pm 0.0173$ & 0.9789 & Fickian \\
SRF201 & $0.1406 \pm 0.0155$ & $0.3028 \pm 0.0216$ & 0.9721 & Fickian \\
SRF301 & $0.1343 \pm 0.0173$ & $0.3043 \pm 0.0251$ & 0.9629 & Fickian \\
SRF203 & $0.2142 \pm 0.0262$ & $0.2417 \pm 0.0244$ & 0.9553 & Fickian \\
SRF205 & $0.2334 \pm 0.0274$ & $0.2315 \pm 0.0235$ & 0.9524 & Fickian \\
\hline
\end{tabular}

Peppas et al. already explained that this equation is accurate for the first $60 \%$ of a release fraction curve [21]. This explanation agrees with our results, as shown in Figure 4 and Figure S1 (in the Supplementary Materials), which depicts the urea fraction released versus time. For more than $60 \%$, the difference in the data between the experimental results and the model calculation is relatively large. It indicates that diffusion transport dominates in the first $60 \%$ of release for all SRF samples. Referred to as the Fickian diffusional release, this mass transfer occurs by the usual molecular diffusion of urea due to the gradient of chemical potential.

The first model describes only the initial kinetic behavior (the release level is less than $60 \%$ ). We have already analyzed the matrix's morphology solely during the immersion to explain the release behavior over the entire range of immersion time (0-504 h). Figure 5 shows the SEM images of neat PLA before (Figure 5A) and after immersion in water for $168 \mathrm{~h}$ (Figure 5B) and $504 \mathrm{~h}$ (Figure 5C). The SEM image in Figure 5A shows a difference in polymer density, indicating the crystalline and amorphous phases in solid poly(lactic acid). The presence of the amorphous phase looks whiter in color and has cracks (shown by arrows). SEM images of PLA after the degradation test in water show significant changes, as seen in Figure 5B,C. The PLA surface became rough and developed numerous micro-holes along the length of the degradation time. 


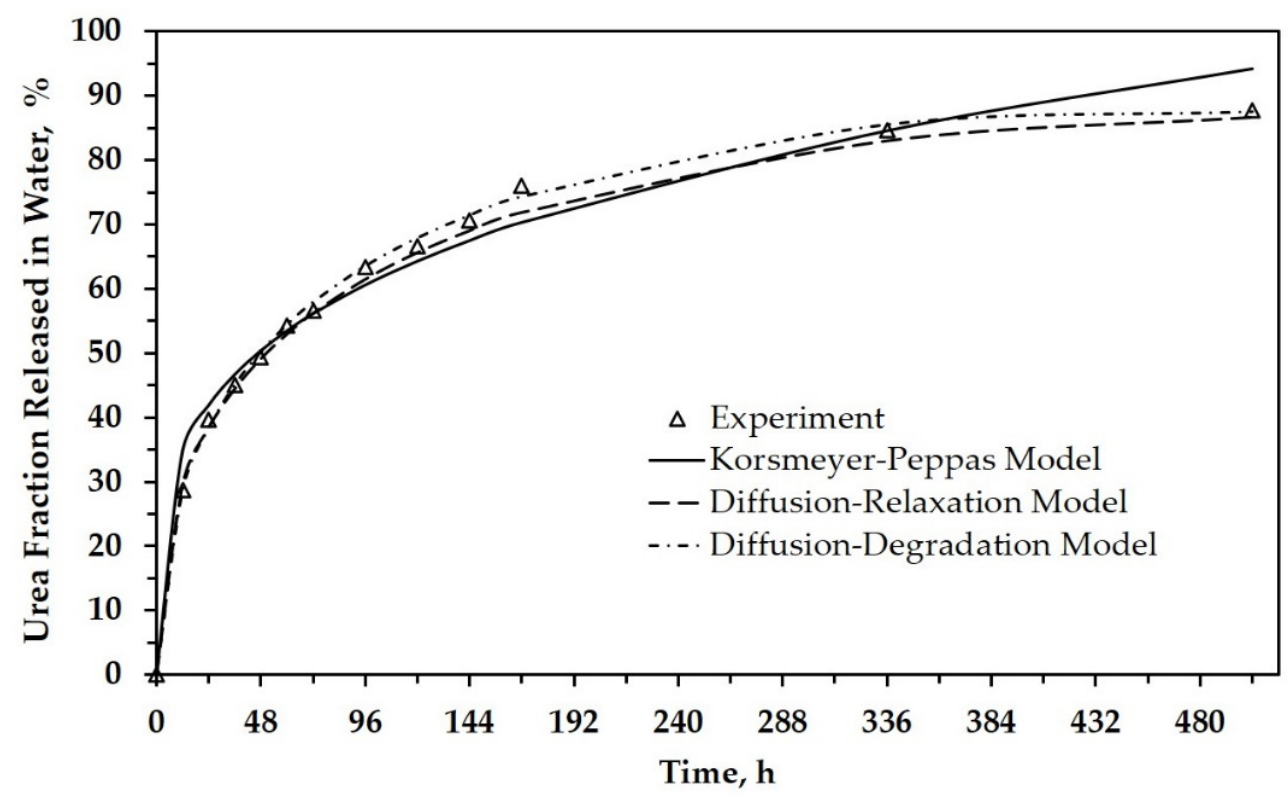

Figure 4. The urea fraction released in water as a function of time for SRF101, based on experimental and calculation data.
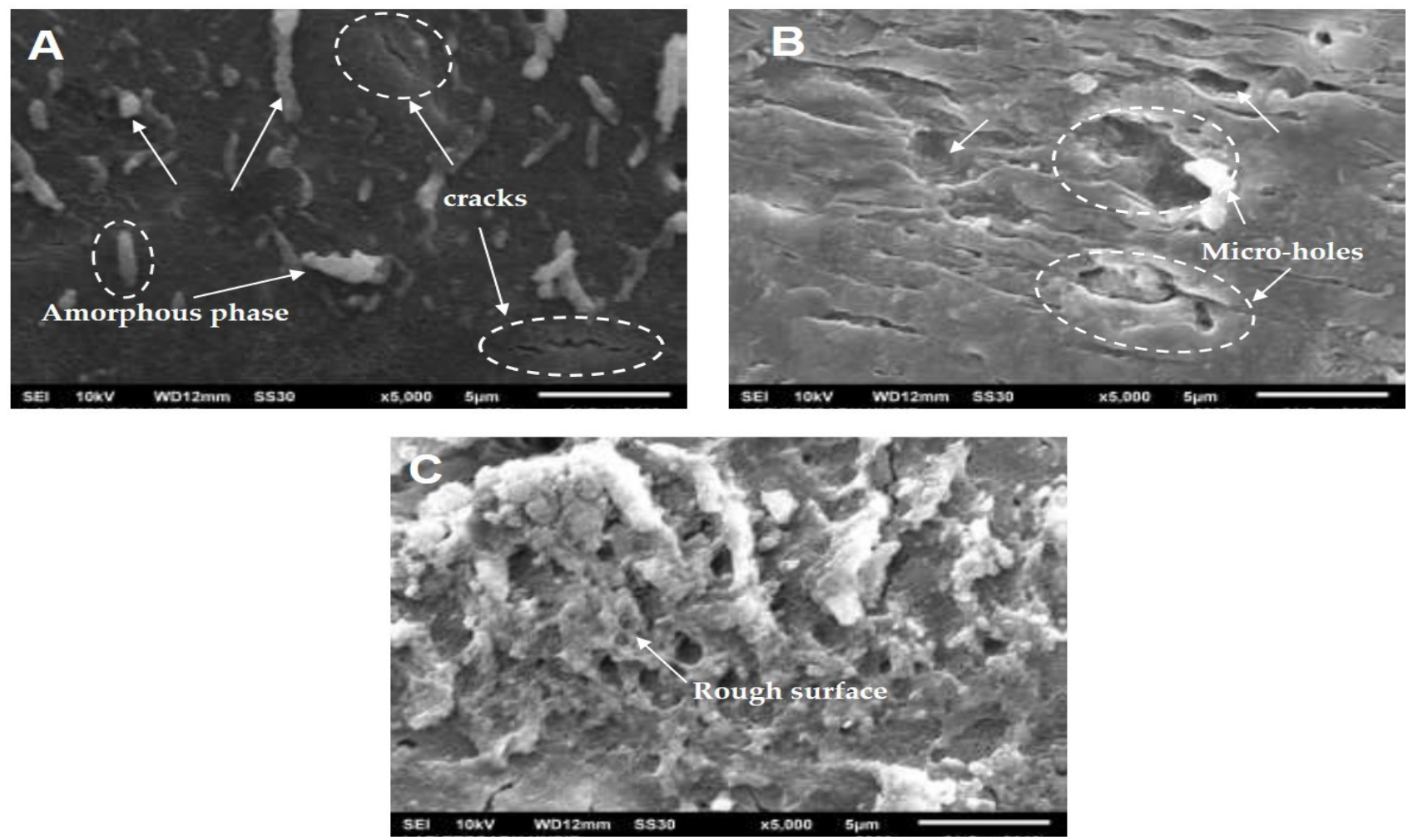

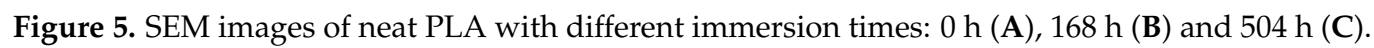

In a previous study, some researchers reported that water diffusion into the amorphous phase initiates the PLA's hydrolytic degradation in aqueous or humid environments. This process involves the scission of PLA chains that are dominant in ester bonds concentrated in this phase to generate a lower $M_{\mathrm{W}}$ PLA or monomer (lactic acid). Thus, the degradation occurs preferentially in the amorphous phase and then continues to the crystalline phase [29-31]. The rough surface and numerous micro-holes could be ascribed to PLA chain scission and removal in both phases. 
In the above explanation, PLA as a matrix is degraded during the hydrolytic degradation test after a certain period. This phenomenon is strongly suspected of affecting urea's release from the matrix, especially after immersion above $96 \mathrm{~h}$ when the solution's $\mathrm{pH}$ tends to decrease more significantly (see Table 2 for neat PLA). Figure 4 shows that the release level of urea is about $60 \%$ after immersion for $96 \mathrm{~h}$. When correlated with the Korsmeyer-Peppas model, several other factors influenced release after $96 \mathrm{~h}$. Thus, we carried out a morphological analysis of SRF samples after immersion for a specific time (Figure 6). This analysis is expected to support a mathematical model that depicts the urea's release throughout the range of time studied.
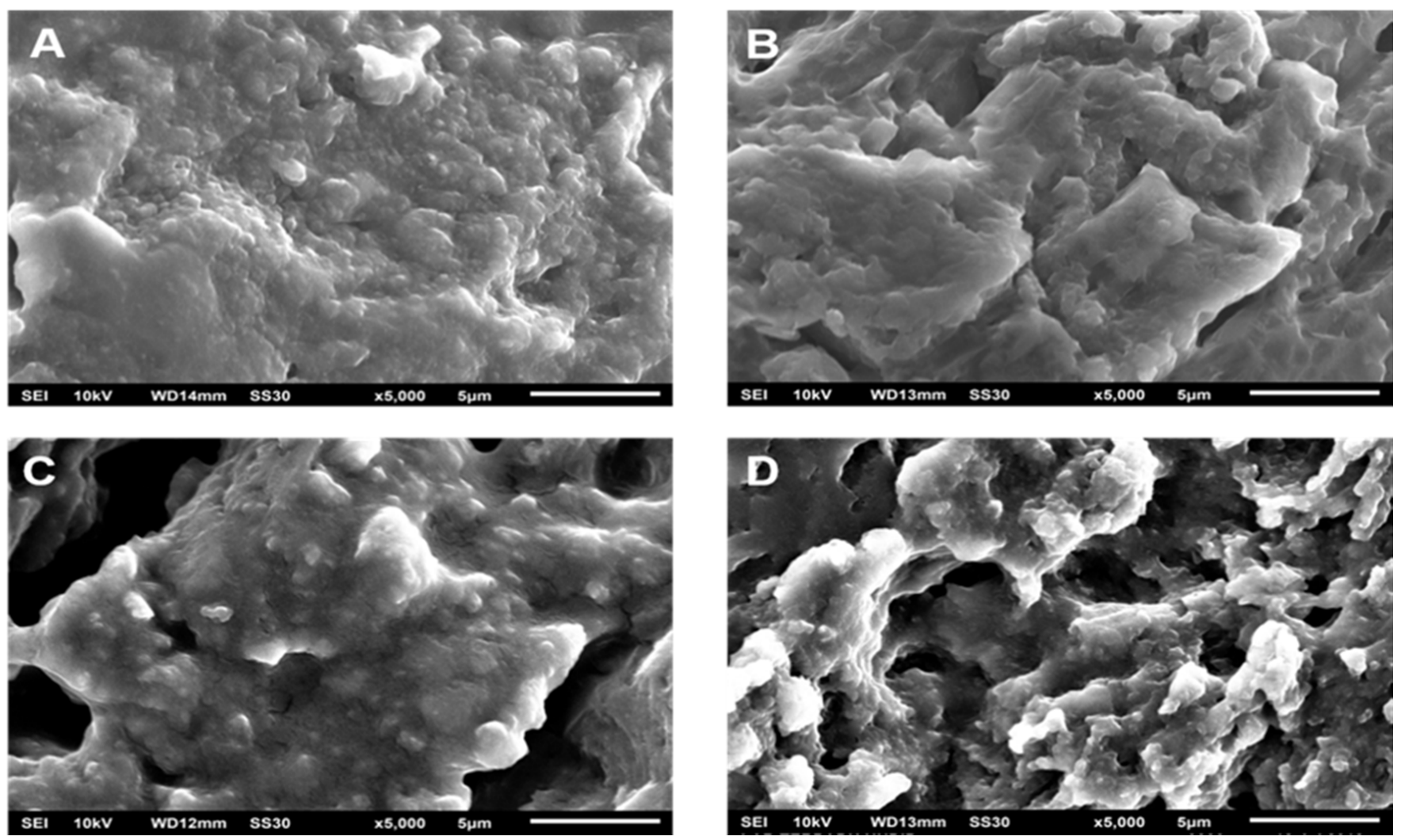

Figure 6. Morphological changes of SRF201 during immersion at different times: $0 \mathrm{~h} \mathrm{(A),} 96 \mathrm{~h}$ (B), $168 \mathrm{~h}$ (C), $504 \mathrm{~h}$ (D).

Figure 6A shows the SRF201's morphology before the process of urea release. The distribution of micro-sized urea is evenly distributed in the PLA matrix with little aggregation being formed. This indicates that the stirring process can disperse the urea. After immersion for $96 \mathrm{~h}$ (see Figure 6B), several holes appeared to be forming, showing a degradation of the polymer matrix. The holes became enlarged and the degradation effect became more visible with increasing immersion times of $168 \mathrm{~h}$ (Figure 6C) and $504 \mathrm{~h}$ (Figure 6D). The existence of these holes may be caused by (i) the initial degradation of PLA in the amorphous area or (ii) the release of urea aggregate (if any) in the SRF samples.

Figure 6 shows that the morphological changes in SRF became more significant above $96 \mathrm{~h}$, but the released urea fraction tended to be less (see Figure 3). This phenomenon illustrates the possibility of different urea release mechanisms before PLA degradation and when the PLA degradation occurred.

As mentioned above, we also examined and verified the curve fit of the experimental data with two models, i.e., the diffusion-relaxation model and the diffusion-degradation model. Both models are used to further describe the release behavior over the entire period of the release time.

Figure 4 depicts the urea release as a function of time for SRF101 based on experimental data and the calculation data. It can be seen that the empirical model also has better 
agreement with experimental release data when relaxation or degradation are considered as parameters in the model. All constants related to both the relaxation and degradation parameters are analyzed and tabulated in Tables 4 and 5. Both tables also tabulate the calculated data's R-squared $\left(R^{2}\right)$, known as the coefficient of determination.

Table 4. Diffusion and relaxation parameters from the diffusion-relaxation model.

\begin{tabular}{cccc}
\hline \multirow{2}{*}{ Sample } & \multicolumn{3}{c}{ Diffusion-Relaxation Model } \\
\cline { 2 - 4 } & $\boldsymbol{k}_{\mathbf{1}}$ & $\boldsymbol{k}_{\mathbf{2}}$ & $\boldsymbol{R}^{\mathbf{2}}$ \\
\hline Neat PLA & - & - & - \\
SRF101 & $0.1119 \pm 1.98 \times 10^{-3}$ & $-0.0036 \pm 1.84 \times 10^{-4}$ & 0.9949 \\
SRF201 & $0.1015 \pm 2.56 \times 10^{-3}$ & $-0.0028 \pm 2.39 \times 10^{-4}$ & 0.9916 \\
SRF301 & $0.0981 \pm 3.16 \times 10^{-3}$ & $-0.0028 \pm 2.95 \times 10^{-4}$ & 0.9865 \\
SRF203 & $0.1284 \pm 2.27 \times 10^{-3}$ & $-0.0047 \pm 2.11 \times 10^{-4}$ & 0.9972 \\
SRF205 & $0.1352 \pm 1.95 \times 10^{-3}$ & $-0.0051 \pm 1.81 \times 10^{-4}$ & 0.9969 \\
\hline
\end{tabular}

Table 5. Diffusion and degradation parameters from the diffusion-degradation model.

\begin{tabular}{|c|c|c|c|c|c|}
\hline \multirow{2}{*}{ Sample } & \multicolumn{5}{|c|}{ Diffusion-Degradation Model } \\
\hline & $a$ & $b$ & $c$ & $d$ & $R^{2}$ \\
\hline Neat PLA & - & - & - & - & - \\
\hline SRF101 & $0.0932 \pm 2.67 \times 10^{-3}$ & $-3.11 \times 10^{-3} \pm 3.86 \times 10^{-4}$ & $2.32 \times 10^{-6} \pm 1.26 \times 10^{-7}$ & $-1.80 \times 10^{-9} \pm 1.51 \times 10^{-7}$ & 0.9987 \\
\hline SRF201 & $0.0705 \pm 2.84 \times 10^{-3}$ & $-7.54 \times 10^{-4} \pm 4.12 \times 10^{-5}$ & $-3.33 \times 10^{-6} \pm 1.35 \times 10^{-7}$ & $3.92 \times 10^{-9} \pm 1.61 \times 10^{-10}$ & 0.9985 \\
\hline SRF301 & $0.0656+5.77 \times 10^{-3}$ & $-6.83 \times 10^{-5}+8.36 \times 10^{-5}$ & $-5.80 \times 10^{-6}+2.74 \times 10^{-7}$ & $6.91 \times 10^{-9}+2.74 \times 10^{-10}$ & 0.9936 \\
\hline SRF203 & $0.0986 \pm 4.19 \times 10^{-3}$ & $-2.91 \times 10^{-3} \pm 6.07 \times 10^{-4}$ & $-6.21 \times 10^{-8} \pm 1.99 \times 10^{-9}$ & $1.10 \times 10^{-9} \pm 2.37 \times 10^{-10}$ & 0.9972 \\
\hline SRF205 & $0.1028 \pm 3.10 \times 10^{-3}$ & $-2.92 \times 10^{-3} \pm 4.48 \times 10^{-4}$ & $-1.23 \times 10^{-6} \pm 1.47 \times 10^{-7}$ & $2.92 \times 10^{-9} \pm 1.75 \times 10^{-10}$ & 0.9984 \\
\hline
\end{tabular}

Table 4 presents the obtained parameters from the data analysis using the diffusionrelaxation model. It can be seen that there is a large gap between the $k_{1}$ and $k_{2}$ constants. Besides that, the $k_{1}$ value is always higher than $k_{2}$. This fact indicates that the diffusion of urea from the PLA matrix dominates its release. The relaxation term only has a minimal effect on diffusion. The negative sign in the $k_{2}$ value indicates a correction for the dominance of diffusion in the model. The $R^{2}$ value of this model shows a better-fitting curve compared with the Korsmeyer-Peppas model.

The $k_{1}$ value tends to decrease proportionally to the increase in the PLA's molecular weight (see SRF101, SRF201, and SRF301). This result verifies the previous statement quantitatively, namely that utilizing the higher $M_{\mathrm{w}}$ poly(lactic acid) tended to inhibit the urea release. The $k_{1}$ value decreased from about 0.1119 to 0.1015 , and 0.0981 , when the PLA's molecular weight increased from 6015.2 to $10,264.7$, and 13,564.2 Da, respectively.

The $k_{1}$ value also describes urea concentration's effect on its release (see SRF201, SRF203, and SRF205). Quantitatively, the $k_{1}$ value increased from about 0.1015 to 0.1284 and 0.1352 when urea concentration was increased from 0.01 to 0.03 and $0.05 \mathrm{~g} / 3 \mathrm{~g}$ of SRF. Again, this result confirms our previous statement that urea's hygroscopic property in the matrix is still in existence and affects its release during immersion.

Table 5 presents the constants obtained from the data analysis using the diffusiondegradation model. This model has better accuracy than the previous two models as shown by the $R^{2}$ value (closer to 1 ). In the data analysis, the constant of $a$, which indicates the diffusion factor, has a much greater value than the other three constants $(b, c$, and $d)$. Again, the obtained data show that diffusion was a dominant factor during urea release. Even though the constant values of $b, c$, and $d$ are very small, they illustrate that other factors influenced the urea release, especially at the release level above $60 \%$ (see Figure 4 ). Because these three factors are related to degradation, it can be highlighted that poly(lactic acid) degradation also influences urea release. The effects of degradation may not be as significant as those caused by diffusion. It might be that PLA begins to degrade after $96 \mathrm{~h}$ of immersion, as previously described. Moreover, most of the urea in the PLA matrix had been released in the solution. 


\subsection{Urea Release Duration}

Table 6 tabulates some materials explored to examine the influence on the urea release rate. These materials were utilized as encapsulating matrices, coating materials, blending materials, etc. It can be seen that different combinations of these materials gave many possibilities for the formulation of slow-release fertilizers. The addition of modifiers that act as binders, fillers, or emulsifiers had different effects on the urea release performance, depending on the property of the modifier itself or the interaction between the modifier and the primary material in the SRF. For example, the hydrophilicity of the modifier in bentonite-based SRF, hydroxypropyl methyl-cellulose (HPMC), was more hydrophilic and induced a faster urea release than that of starch [9]. A different result was reported by Pereira et al. [6], namely that the hydrophilicity causes a good interaction between polyacrylamide hydrogels and bentonite, resulting in a slower release of urea compared with polycaprolactone.

The addition of emulsifiers, such as span-80, increased the dispersity of the sealant in sulfur-based SRF. Yu and Li reported that brittle paraffin's coating efficiency as a hydrophobic sealant was improved due to the span-80 enhancing its adhesion [15]. Both synthetic and natural polymers were also explored as coating materials or matrices. The formulation of the hydrophilicity and hydrophobicity of the polymers and modifiers significantly influenced the release pattern [16,32-36].

Table 6 provides an overview of several successful attempts to slow urea's release with varying release durations. The utilization of inorganic materials and synthetic polymers in SRF raises problems on the other side. Fertilization with sulfur-coated urea (SCU) has the potential to improve soil acidity. However, polymer and minerals in SRF will leave the residue, contributing to other forms of pollution, and they are difficult to degrade properly in the soil [12]. In this study, the release duration of the obtained SRFs was about $168 \mathrm{~h}$ to achieve $75 \%$ urea release when tested in water. This result is comparable with the other results, as shown in Table 6 . This SRF utilized the low molecular weight poly(lactic acid) without any other additives or modifiers. Thus, this fertilizer is promising because it does not leave residues that damage the soil structure and the nutrient balance in the soil. PLA can be naturally degraded into substances that are not toxic and harmful to plants $[17,18]$.

Table 6. The urea release duration of slow-release fertilizer (SRF) conducted in this work and some other reports.

\begin{tabular}{|c|c|c|c|c|}
\hline Material + Modifier (Additive) & Preparation Method & Release Test & * Release Duration & Ref. \\
\hline $\begin{array}{c}\text { Mineral } \\
\text { Natural bentonite + binder: corn starch or } \\
\text { hydroxypropyl methyl-cellulose } \\
\text { Montmorillonite clay (bentonite) + } \\
\text { hydrophobic/hydrophilic polymer: } \\
\text { polycaprolactone or polyacrylamide hydrogel }\end{array}$ & $\begin{array}{l}\text { Melt blending } \\
\text { Melt blending }\end{array}$ & $\begin{array}{l}\text { Higuchi procedure in } \\
\text { water at } 30^{\circ} \mathrm{C} \\
\text { Immersed in an aqueous } \\
\text { medium at room } \\
\text { temperature }\end{array}$ & $\begin{array}{l}118 \mathrm{~h} \text { or } 48 \mathrm{~h} \\
30 \mathrm{~h} \text { or } 60 \mathrm{~h}\end{array}$ & $\begin{array}{l}{[9]} \\
{[6]}\end{array}$ \\
\hline Phosphogypsum + paraffin wax + span-80 & Coating & $\begin{array}{l}\text { Static release test in water } \\
\text { at } 25^{\circ} \mathrm{C}\end{array}$ & $240 \mathrm{~h}$ & {$[15]$} \\
\hline $\begin{array}{c}\text { Synthetic polymer } \\
\text { Polyurethane + mesoporous silica } \\
\text { Polystyrene + wax } \\
\text { Polystyrene + polyurethane }\end{array}$ & Coating & $\begin{array}{l}\text { Immersed in deionized } \\
\text { water at } 25^{\circ} \mathrm{C} \\
\text { Immersed in deionized } \\
\text { water at } 25^{\circ} \mathrm{C}\end{array}$ & $\begin{array}{l}10-50 \mathrm{~d} \\
42 \mathrm{~d} \\
70 \mathrm{~d}\end{array}$ & $\begin{array}{l}{[33]} \\
{[34]}\end{array}$ \\
\hline $\begin{array}{l}\frac{\text { Degradable synthetic polymer }}{\text { Polyesters: poly(hexamethylene succinate) } / \text { PHS }} \\
\text { Polyvinyl alcohol + biochar }\end{array}$ & Melt blending & $\begin{array}{l}\text { Immersed in deionized } \\
\text { water at } 25^{\circ} \mathrm{C} \\
\text { Buried in soil column } \\
\text { experiment at } 25^{\circ} \mathrm{C}\end{array}$ & $400 \mathrm{~h}$ & [16] \\
\hline $\begin{array}{c}\frac{\text { Natural polymer }}{\text { Starch }+ \text { glycerol }} \\
\text { Alginate }+\begin{array}{l}\text { K-carrageenan / celite superabsorbent } \\
\text { Chitosan salicylaldehyde }\end{array} \\
\text { Poly(lactic acid) with a low molecular weight }\end{array}$ & $\begin{array}{l}\text { Coating } \\
\text { Coating } \\
\text { Solvent casting }\end{array}$ & $\begin{array}{c}\text { Buried in compost soil } \\
\text { at } 25^{\circ} \mathrm{C} \\
\text { Buried in soil at } 25^{\circ} \mathrm{C} \\
\text { Immersed in distilled } \\
\text { water at } 25^{\circ} \mathrm{C} \\
\text { Static release test in water } \\
\text { at } 30^{\circ} \mathrm{C}\end{array}$ & $15-30 \mathrm{~d}$ & $\begin{array}{l}{[32]} \\
{[35]} \\
{[36]}\end{array}$ \\
\hline
\end{tabular}




\section{Conclusions}

Slow-release fertilizer (SRF) with urea was successfully synthesized through melt blending between low molecular weight poly(lactic acid) and urea. Through the FTIR spectra and SEM images, we can confirm the presence of urea and its distribution in the SRF. To investigate the urea release mechanism of SRFs in water, we obtained the fractional release data of urea from static release experiments and we evaluated these data by fitting the curve of the fractional release through three mathematical models. It was found that a higher urea concentration in the SRF exhibited a faster release of urea. The hygroscopic property of urea could still exist and influence the release process. Utilizing the higher molecular weight poly(lactic acid) had a slower urea release due to the decreasing permeability of PLA. The low permeability inhibited the contact between water and urea in the PLA matrix. The diffusion-degradation model showed the best match between all samples' release behavior and the mathematical approaches compared with the other two models. However, the three studied models showed the same tendency that diffusion within the matrix dominated the urea release process, especially when the release level was less than $60 \%$. The erosion (in this case, as hydrolytic degradation) of the PLA matrix may begin after $120 \mathrm{~h}$ of immersion. This immersion time indicates that the urea release level was around $60 \%$. Thus, above this level, the degradation factor began to appear and, in the model, it had the best match with the experimental data. This SRF is promising because it does not leave residues that damage the soil structure and the nutrient balance in the soil.

Supplementary Materials: The following are available online at https://www.mdpi.com/article/10 $.3390 /$ polym13111856/s1. Table S1: Urea concentration in water during the urea release test. Figure S1: The urea fraction released in water as a function of time based on the experimental and calculated data: (a) SRF201, (b) SRF301, (c) SRF203, and (d) SRF205.

Author Contributions: Conceptualization, all authors; methodology, M.K. and S.D.; validation, M.K. and E.N.S.; investigation, E.N.S.; writing—original draft preparation, E.N.S.; writing-review and editing, M.K. and S.D.; visualization, M.K. and S.D.; supervision, M.K. All authors have read and agreed to the published version of the manuscript.

Funding: This research was funded by the Ministry of Research Technology and Higher Education (PTUPT research scheme) in 2018, grant number 089/SP2H/LT/DRPM/2018. The APC was funded by the Institute of Research and Community Service, Universitas Sebelas Maret, Indonesia.

Institutional Review Board Statement: Not Applicable.

Informed Consent Statement: Not Applicable.

Data Availability Statement: Data are contained within the article.

Conflicts of Interest: The authors declare no conflict of interest. The funders had no role in the design of the study; in the collection, analyses, or interpretation of data; in the writing of the manuscript; or in the decision to publish the results.

\section{References}

1. Forleo, M.B.; Palmieri, N.; Suardi, A.; Coaloa, D.; Pari, L. The eco-efficiency of rapeseed and sunflower cultivation in italy. Joining environmental and economic assessment. J. Clean. Prod. 2018, 172, 3138-3153. [CrossRef]

2. Dwivedi, S.L.; Lammerts van Bueren, E.T.; Ceccarelli, S.; Grando, S.; Upadhyaya, H.D.; Ortiz, R. Diversifying food systems in the pursuit of sustainable food production and healthy diets. Trends Plant Sci. 2017, 22, 842-856. [CrossRef]

3. Miao, Y.; Stewart, B.A.; Zhang, F. Long-term experiments for sustainable nutrient management in china. A review. Agron. Sustain. Dev. 2011, 31, 397-414. [CrossRef]

4. Pypers, P.; Sanginga, J.-M.; Kasereka, B.; Walangululu, M.; Vanlauwe, B. Increased productivity through integrated soil fertility management in cassava-legume intercropping systems in the highlands of sud-kivu, dr congo. Field Crop. Res. 2011, 120, 76-85. [CrossRef]

5. Chien, S.H.; Teixeira, L.A.; Cantarella, H.; Rehm, G.W.; Grant, C.A.; Gearhart, M.M. Agronomic effectiveness of granular nitrogen/phosphorus fertilizers containing elemental sulfur with and without ammonium sulfate: A review. Agron. J. 2016, 108, 1203-1213. [CrossRef] 
6. Pereira, E.I.; da Cruz, C.C.T.; Solomon, A.; Le, A.; Cavigelli, M.A.; Ribeiro, C. Novel slow-release nanocomposite nitrogen fertilizers: The impact of polymers on nanocomposite properties and function. Ind. Eng. Chem. Res. 2015, 54, 3717-3725. [CrossRef]

7. Dubey, A.; Mailapalli, D.R. Development of control release urea fertilizer model for water and nitrogen movement in flooded rice. Paddy Water Environ. 2018, 16, 1-13. [CrossRef]

8. Xiaoyu, N.; Yuejin, W.; Zhengyan, W.; Lin, W.; Guannan, Q.; Lixiang, Y. A novel slow-release urea fertiliser: Physical and chemical analysis of its structure and study of its release mechanism. Biosyst. Eng. 2013, 115, 274-282. [CrossRef]

9. Hermida, L.; Agustian, J. Slow release urea fertilizer synthesized through recrystallization of urea incorporating natural bentonite using various binders. Environ. Technol. Innov. 2019, 13, 113-121. [CrossRef]

10. Spiertz, J.H.J. Nitrogen, sustainable agriculture and food security. A review. Agron. Sustain. Dev. 2010, 30, 43-55. [CrossRef]

11. Jat, R.A.; Wani, S.P.; Sahrawat, K.L.; Singh, P.; Dhaka, S.R.; Dhaka, B.L. Recent approaches in nitrogen management for sustainable agricultural production and eco-safety. Arch. Agron. Soil Sci. 2012, 58, 1033-1060. [CrossRef]

12. Lawrencia, D.; Wong, S.K.; Low, D.Y.S.; Goh, B.H.; Goh, J.K.; Ruktanonchai, U.R.; Soottitantawat, A.; Lee, L.H.; Tang, S.Y Controlled release fertilizers: A review on coating materials and mechanism of release. Plants 2021, 10, 238. [CrossRef] [PubMed]

13. Latifah, O.; Ahmed, O.H.; Majid, N.M.A. Enhancing nitrogen availability from urea using clinoptilolite zeolite. Geoderma 2017, 306, 152-159. [CrossRef]

14. Lateef, A.; Nazir, R.; Jamil, N.; Alam, S.; Shah, R.; Khan, M.N.; Saleem, M. Synthesis and characterization of zeolite based nano-composite: An environment friendly slow release fertilizer. Microporous Mesoporous Mater. 2016, 232, 174-183. [CrossRef]

15. Yu, X.; Li, B. Release mechanism of a novel slow-release nitrogen fertilizer. Particuology 2019, 45, 124-130. [CrossRef]

16. Chen, S.; Yang, M.; Ba, C.; Yu, S.; Jiang, Y.; Zou, H.; Zhang, Y. Preparation and characterization of slow-release fertilizer encapsulated by biochar-based waterborne copolymers. Sci. Total Environ. 2018, 615, 431-437. [CrossRef]

17. Qi, X.; Ren, Y.; Wang, X. New advances in the biodegradation of poly(lactic) acid. Int. Biodeterior. Biodegrad. 2017, 117, 215-223. [CrossRef]

18. Valentina, I.; Haroutioun, A.; Fabrice, L.; Vincent, V.; Roberto, P. Poly(lactic acid)-based nanobiocomposites with modulated degradation rates. Materials 2018, 11, 1943. [CrossRef]

19. Kaavessina, M.; Distantina, S.; Chafidz, A.; Fadilah; Al-Zahrani, S. The influences of elastomer toward degradability of poly (lactic acid). Aip Conf. Proc. 2016, 1710, 030031.

20. Kaavessina, M.; Chafidz, A.; Distantina, S.; Al-Zahrani, S.M. Characterization of poly (lactic acid) synthesized via direct polycondensation with different treatments of sncl2 as a catalyst. Arpn J. Eng. Appl. Sci. 2016, 11, 9992-9998.

21. Ritger, P.L.; Peppas, N.A. A simple equation for description of solute release ii. Fickian and anomalous release from swellable devices. J. Control. Release 1987, 5, 37-42. [CrossRef]

22. Dash, S.; Murthy, P.N.; Nath, L.; Chowdhury, P. Kinetic modeling on drug release from controlled drug delivery systems. Acta Pol. Pharm. 2010, 67, 217-223.

23. Peppas, N.A.; Sahlin, J.J. A simple equation for the description of solute release. Iii. Coupling of diffusion and relaxation. Int. J. Pharm. 1989, 57, 169-172. [CrossRef]

24. Bi, S.; Barinelli, V.; Sobkowicz, M.J. Degradable controlled release fertilizer composite prepared via extrusion: Fabrication, characterization, and release mechanisms. Polymers 2020, 12, 301. [CrossRef]

25. Garlotta, D. A literature review of poly(lactic acid). J. Polym. Environ. 2001, 9, 63-84. [CrossRef]

26. Manivannan, M.; Rajendran, S. Investigation of inhibitive action of urea-zn2+ system in the corrosion control of carbon steel in sea water. Int. J. Eng. Sci. Technol. 2011, 3, 8048-8060.

27. Bull, H.B.; Breese, K.; Ferguson, G.L.; Swenson, C.A. The ph of urea solutions. Arch. Biochem. Biophys. 1964, 104, 297-304 [CrossRef]

28. Upadrashta, S.; Katikaneni, P.; Hileman, G.; Keshary, P. Direct compression controlled release tablets using ethylcellulose matrices. Drug Dev. Ind. Pharm. 2008, 19, 449-460. [CrossRef]

29. Kaavessina, M.; Chafidz, A.; Ali, I.; Al-Zahrani, S.M. Characterization of poly(lactic acid)/hydroxyapatite prepared by a solvent-blending technique: Viscoelasticity and in vitro hydrolytic degradation. J. Elastomers Plast. 2014, 47, 753-768. [CrossRef]

30. Elsawy, M.; Kim, K.-H.; Park, J.-W.; Deep, A. Hydrolytic degradation of polylactic acid (pla) and its composites. Renew. Sustain. Energy Rev. 2017, 79, 1346-1352. [CrossRef]

31. Ndazi, B.S.; Karlsson, S. Characterization of hydrolytic degradation of polylactic acid/rice hulls composites in water at different temperatures. Express Polym. Lett. 2011, 5, 119-131. [CrossRef]

32. Versino, F.; Urriza, M.; García, M.A. Eco-compatible cassava starch films for fertilizer controlled-release. Int. J. Biol. Macromol. 2019, 134, 302-307. [CrossRef]

33. Li, L.; Sun, Y.; Cao, B.; Song, H.; Xiao, Q.; Yi, W. Preparation and performance of polyurethane/mesoporous silica composites for coated urea. Mater. Des. 2016, 99, 21-25. [CrossRef]

34. Yang, Y.-c.; Zhang, M.; Li, Y.; Fan, X.-h.; Geng, Y.-q. Improving the quality of polymer-coated urea with recycled plastic, proper additives, and large tablets. J. Agric. Food Chem. 2012, 60, 11229-11237. [CrossRef] 
35. Wang, Y.; Liu, M.; Ni, B.; Xie, L. K-carrageenan-sodium alginate beads and superabsorbent coated nitrogen fertilizer with slow-release, water-retention, and anticompaction properties. Ind. Eng. Chem. Res. 2012, 51, 1413-1422. [CrossRef]

36. Iftime, M.M.; Ailiesei, G.L.; Ungureanu, E.; Marin, L. Designing chitosan based eco-friendly multifunctional soil conditioner systems with urea controlled release and water retention. Carbohydr. Polym. 2019, 223, 115040. [CrossRef] 